Article

\title{
Importance of $\boldsymbol{H}$-Abstraction in the Final Step of Nitrosoalkane Formation in the Mechanism-Based Inactivation of Cytochrome P450 by Amine-Containing Drugs
}

\author{
Hajime Hirao *, Nandun M. Thellamurege, Pratanphorn Chuanprasit and Kai Xu \\ Division of Chemistry and Biological Chemistry, School of Physical and Mathematical Sciences, \\ Nanyang Technological University, 21 Nanyang Link 637371, Singapore; \\ E-Mails: nandun.t@ntu.edu.sg, (N.M.T.); pratanph001@e.ntu.edu.sg (P.C.); \\ xuka0004@e.ntu.edu.sg (K.X.) \\ * Author to whom correspondence should be addressed; E-Mail: hirao@ntu.edu.sg; \\ Tel.: +65-6592-2644; Fax: +65-6791-1961.
}

Received: 13 October 2013; in revised form: 27 November 2013 / Accepted: 29 November 2013 / Published: 18 December 2013

\begin{abstract}
The metabolism of amine-containing drugs by cytochrome P450 enzymes (P450s) is prone to form a nitrosoalkane metabolic intermediate (MI), which subsequently coordinates to the heme iron of a $\mathrm{P} 450$, to produce a metabolic-intermediate complex (MIC). This type of P450 inhibition, referred to as mechanism-based inactivation (MBI), presents a serious concern in drug discovery processes. We applied density functional theory (DFT) to the reaction between $N$-methylhydroxylamine (NMH) and the compound I reactive species of $\mathrm{P} 450$, in an effort to elucidate the mechanism of the putative final step of the MI formation in the alkylamine metabolism. Our DFT calculations show that $H$-abstraction from the hydroxyl group of NMH is the most favorable pathway via which the nitrosoalkane intermediate is produced spontaneously. $H$-abstraction from the $\mathrm{N}-\mathrm{H}$ bond was slightly less favorable. In contrast, $\mathrm{N}$-oxidation and $\mathrm{H}$-abstraction from the $\mathrm{C}-\mathrm{H}$ bond of the methyl group had much higher energy barriers. Hence, if the conversion of NMH to nitrosoalkane is catalyzed by a $\mathrm{P} 450$, the reaction should proceed preferentially via $\mathrm{H}$-abstraction, either from the $\mathrm{O}-\mathrm{H}$ bond or from the $\mathrm{N}-\mathrm{H}$ bond. Our theoretical analysis of the interaction between the MI and pentacoordinate heme moieties provided further insights into the coordination bond in the MIC.
\end{abstract}


Keywords: cytochrome $\mathrm{P} 450$; mechanism-based inactivation; reaction mechanism; metabolic-intermediate complex; density functional theory; energy decomposition analysis

\section{Introduction}

Human cytochrome P450 enzymes (P450s) are known as versatile biological catalysts with remarkably broad substrate specificity [1-14]. A variety of different drugs are metabolized by only a few P450 isozymes, mainly by CYP2B6, CYP2C9, CYP2C19, CYP2D6, and CYP3A4 [15]. Malfunction of these P450s through drug-drug interaction (DDI) is causally linked to unfavorably altered metabolic profiles of compounds. In silico methods hold significant promise for predicting and minimizing the risks of DDIs at an early stage of a drug discovery project. However, in silico description of a particular type of DDI, referred to as mechanism-based inactivation (MBI) [16-23], presents a difficult challenge because MBI occurs via P450-catalyzed metabolic intermediate (MI) formation. To describe such reactive processes computationally, one must resort to quantum chemistry. In recent years, quantum chemical studies of P450 MBI using density functional theory (DFT) have become increasingly prevalent [24-29].

Of all compounds that inhibit P450s through DDI or MBI, alkylamines are a particularly important class because they include a number of drugs such as calcium channel blockers (Scheme 1), macrolide antibiotics, monoamine oxidase inhibitors, etc. [30-34] Tertiary, secondary, and primary alkylamines have been reported to cause quasi-irreversible-type MBI via formation of a nitrosoalkane MI. As illustrated in Scheme 2, a tertiary alkylamine (1) is dealkylated to a secondary alkylamine (2) [35-37], which means that tertiary and secondary alkylamines follow a common pathway for the formation of a MI (7). The metabolism of secondary alkylamine is somewhat controversial, because 2 may follow either path I or II [38]. However, it is often believed that a $N$-hydroxyalkylamine intermediate (4) is formed in either case, just before the MI formation [19,22,23,39,40]. The conversion of 4 to 7 may therefore be regarded as a critical step that all alkylamines pass through, before forming a MI. The resultant MI coordinates to the ferrous heme iron to form a MI complex (MIC, 8), which is directly responsible for the enzyme inhibition and features a Soret absorbance peak at $\sim 455 \mathrm{~nm}$ [41].

Scheme 1. Examples of amine-containing calcium channel blockers that act as mechanism-based inactivators.

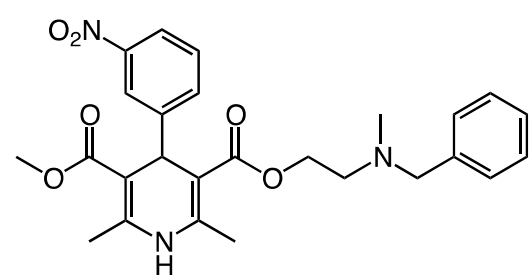

Nicardipine<smiles>COc1ccc(CCN(C)CCCC(C#N)(c2ccc(OC)c(OC)c2)C(C)C)cc1OC</smiles>

Verapamil

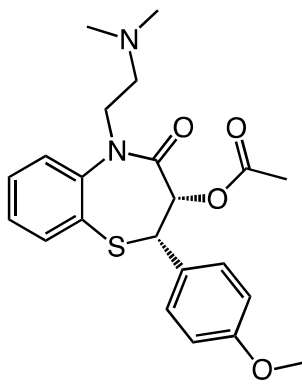

Diltiazem 
Scheme 2. Possible pathways of metabolic-intermediate complex (MIC) formation starting from a tertiary amine [38]. Some of the alkyl groups are replaced by $\mathrm{CH}_{3}$ for simplicity.

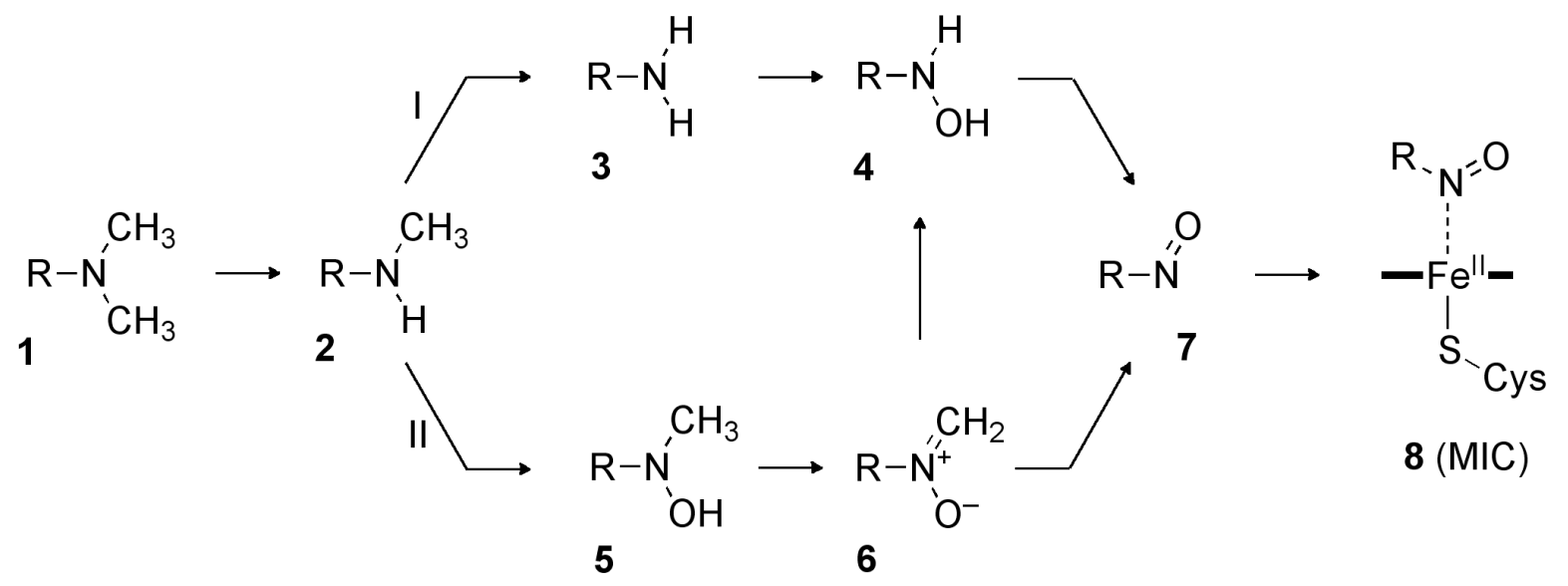

This study is particularly concerned with the putative final step of the nitrosoalkane MI formation, i.e., conversion of $\mathbf{4}$ to 7 and the coordination of 7 to the heme. We examine the mechanism in which an oxoiron(IV) porphyrin $\pi$-cation radical intermediate, compound I (Cpd I), of a P450, is responsible for this oxidative process, although it should be mentioned that 4 may not always require a P450 for the oxidation because it readily undergoes autoxidation $[39,42]$. As this step is not well explored, we here attempt to find a plausible reaction mechanism using density functional theory (DFT) calculations. Moreover, we investigate the nature of the coordination bonds in ferrous and ferric MICs.

\section{Results and Discussion}

\subsection{Models}

For the calculations, we used a Cpd I model as depicted in Scheme 3a. The $\mathrm{R}$ group of $\mathrm{N}$-alkylhydroxylamine (4) in Scheme 2 was assumed to be $\mathrm{CH}_{3}$; that is, $\mathrm{N}$-methylhydroxylamine (NMH) was used (Scheme 3b). As shown in Scheme 3b, four possible pathways A-D for the reactions between Cpd I and 4 were considered, which respectively begin with $\mathrm{H}$-abstraction from the $\mathrm{O}-\mathrm{H}$ bond (path A), $\mathrm{H}$-abstraction from the $\mathrm{N}-\mathrm{H}$ bond (path B), $\mathrm{N}$-oxidation (path $\mathrm{C}$ ), and $\mathrm{H}$-abstraction from the methyl group (path D). It did not seem plausible that electron transfer occurs from the substrate to Cpd I prior to bond formation (Scheme S1).

Scheme 3. (a) Cpd I model; (b) Hydroxylamine and three possible pathways considered (paths A-D); and (c) MIC model.

(a)

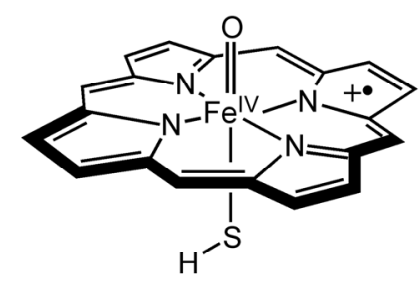

P450 Cpd I mode (b)

(C) N-oxidation

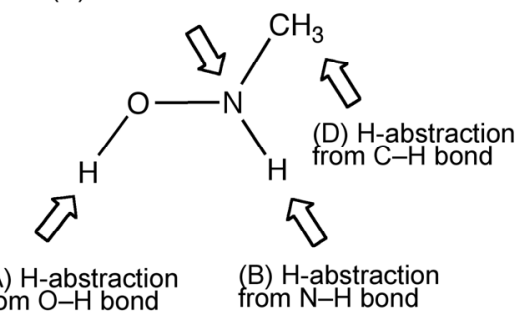

(c)

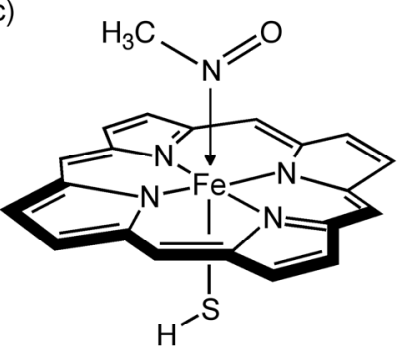

MIC model 


\subsection{Reaction Mechanism}

The energy profiles for all four pathways are presented in Figure 1, and the optimized intermediates and transition states are shown in Figure 2. Raw energy data, group spin populations, and group atomic charges for all species are summarized in Tables S1-S5. The XYZ coordinates of optimized geometries are also available in the Supporting Information.

The energy profile and key geometries for path A are presented in Figures 1a and 2a, respectively. The reactant complex on this path (RCa) is stabilized by a hydrogen bond ( $\mathrm{H}$ bond) between the hydroxyl group of NMH and the oxo moiety of Cpd I. The first $H$-abstraction occurs through a transition state, TS1a. TS1a is lower in energy by $0.3 \mathrm{kcal} / \mathrm{mol}$ than $\mathbf{R C a}$, indicating that the $H$-abstraction step is barrierless. The $H$-abstraction leads to an intermediate, INT1a, which is a weakly interacting complex of ferryl-type Cpd II and a substrate radical. Subsequently, another hydrogen atom is abstracted from the $\mathrm{N}-\mathrm{H}$ bond to form a product complex, PROa. There is no noticeable barrier in the second $H$-abstraction.

As seen in Figures $1 b$ and $2 b$, path $\mathrm{B}$ begins by forming a reactant complex, $\mathbf{R C b}$, which is stabilized by a $\mathrm{H}$ bond between the $\mathrm{N}-\mathrm{H}$ bond of $\mathrm{NMH}$ and $\mathrm{Cpd}$ I. RCb is less stable than RCa by only a few $\mathrm{kcal} / \mathrm{mol}$, and the first $H$-abstraction from the $\mathrm{N}-\mathrm{H}$ bond via $\mathbf{T S b}$ has a small energy barrier of $\sim 2 \mathrm{kcal} / \mathrm{mol}$. The $H$-abstraction leads to an intermediate, INT1b, which is a complex of Cpd II and a substrate radical. The second $H$-abstraction from the $\mathrm{O}-\mathrm{H}$ bond en route to PROb has no barrier. Thus, the energy diagrams for the two $H$-abstraction pathways (paths A and B) in Figure 1a,b suggest that the MI formation from 4 through these pathways should be remarkably facile.

In contrast, the energy barrier $(13.3 \mathrm{kcal} / \mathrm{mol})$ existing on the $N$-oxidation pathway (path $\mathrm{C}$, see Figure 1c) is much higher than those for paths A and B. Furthermore, a recent DFT study done by Taxak et al. [26] showed that the $N$-oxidation intermediate, INT1c, is subsequently converted to a $\mathrm{N}, \mathrm{N}$-dihydroxy-type diol intermediate, and that the dehydration of the diol has a very high energy barrier $(\sim 35 \mathrm{kcal} / \mathrm{mol})$. It therefore seems reasonable to conclude that the reaction does not choose path C over path A or B for the MIC formation.

The energy barrier for $H$-abstraction from the methyl group $(11.2 \mathrm{kcal} / \mathrm{mol})$ on path $\mathrm{D}$ is somewhat lower than that for path $\mathrm{C}$ (Figure $1 \mathrm{~d}$ ). The $H$-abstraction from a $\mathrm{C}-\mathrm{H}$ bond is followed by another spontaneous $\mathrm{H}$-abstraction from the $\mathrm{O}-\mathrm{H}$ bond, resulting in the formation of formaldonitrone at PROd. However, the barrier for path D is still much higher than those for paths A and B; thus, it is less likely that the reaction follows path D. Interestingly, the bond dissociation energies of the $\mathrm{O}-\mathrm{H}$, $\mathrm{N}-\mathrm{H}$, and $\mathrm{C}-\mathrm{H}$ bonds correlated well with the calculated barrier heights for $H$-abstraction from these bonds (Table S6).

Taken together, our calculations suggest that species $\mathbf{4}$ is converted to $\mathbf{7}$ via path A or B. 
Figure 1. Energy diagrams (in $\mathrm{kcal} / \mathrm{mol}$ ) for (a) path $\mathrm{A}$; (b) path $\mathrm{B}$; (c) path $\mathrm{C}$; and (d) path $\mathrm{D}$, obtained at the B3LYP(SCRF)/B2//M06/B1 level with zero-point energy corrections.

(a) path $\mathrm{A}$

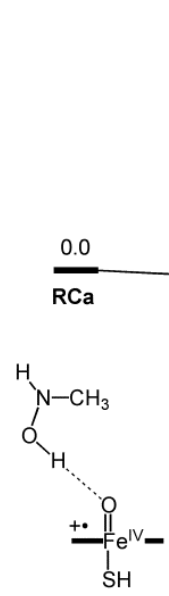

$\stackrel{\mathrm{H}}{\mathrm{N}-\mathrm{CH}_{3}}$

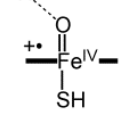

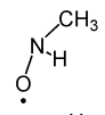

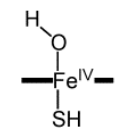

(c) path $\mathrm{C}$

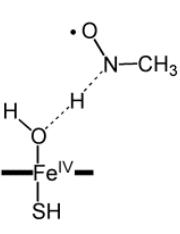

(c) path

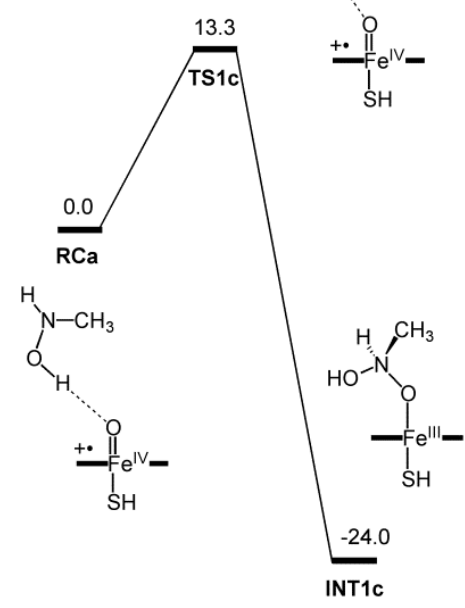

(b) path $B$

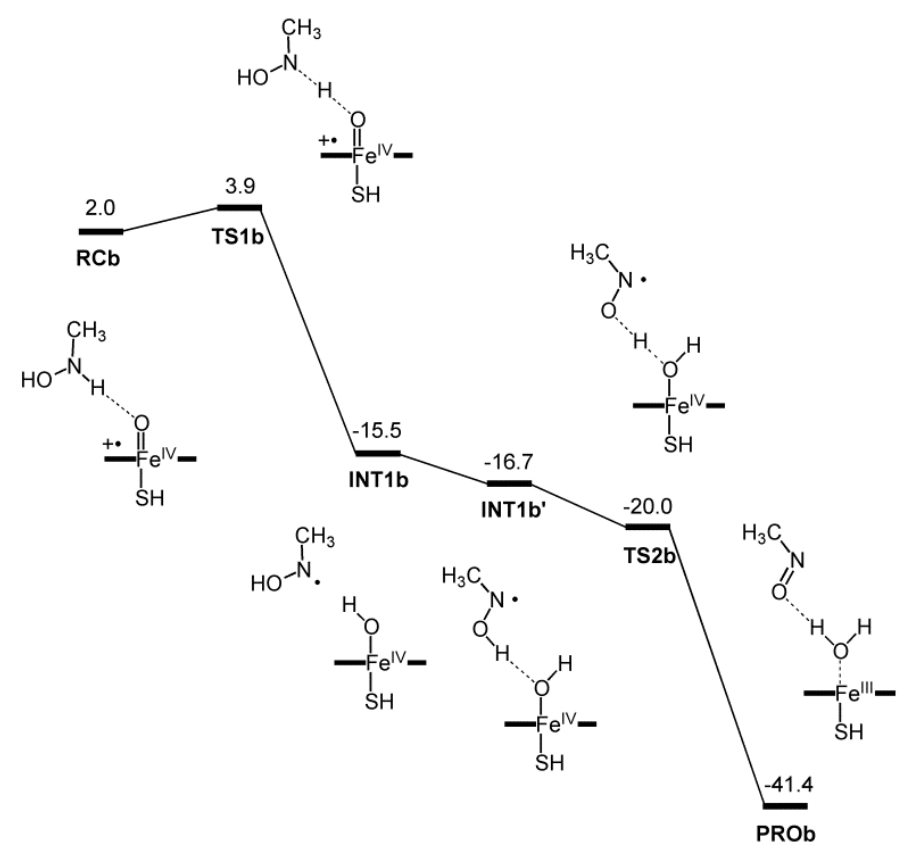

(d) path D

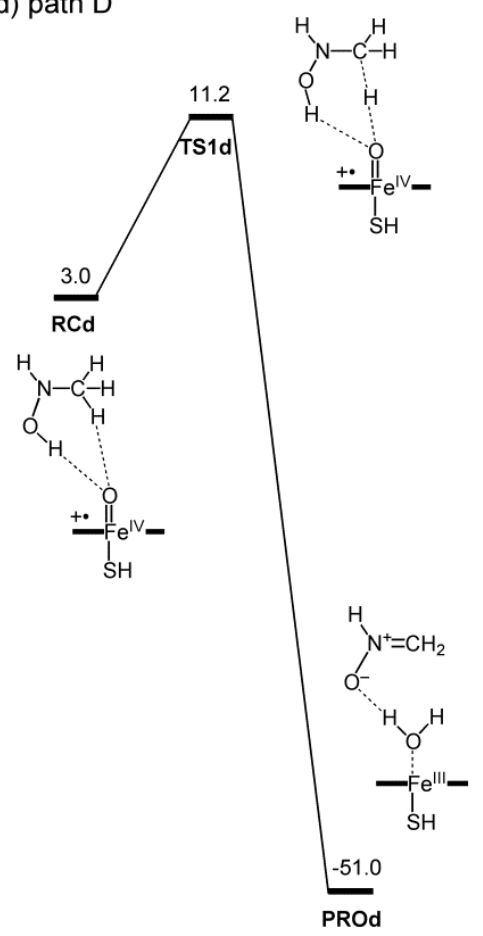


Figure 2. Optimized geometries of species on (a) path A; (b) path B; (c) path C; and (d) path D. Key bond distances are shown in $\AA$.
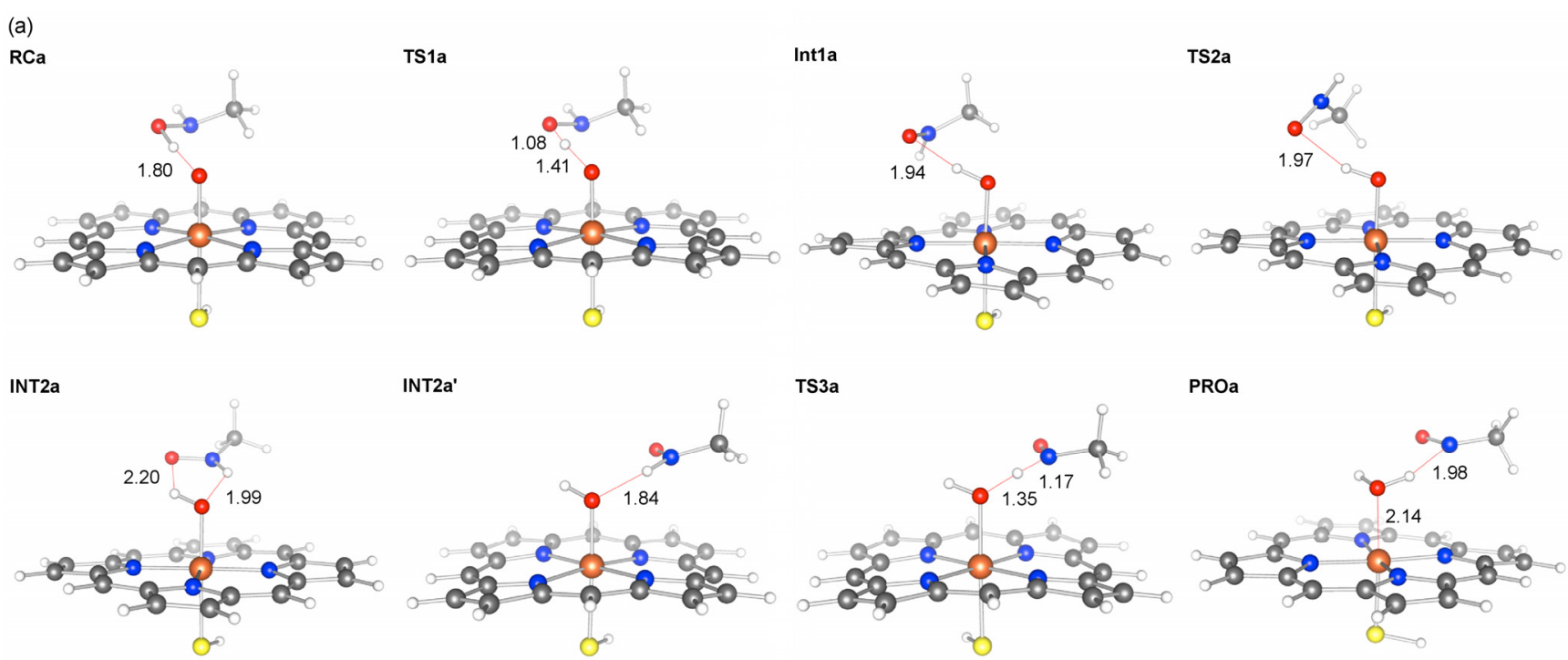

TS3a

PROa
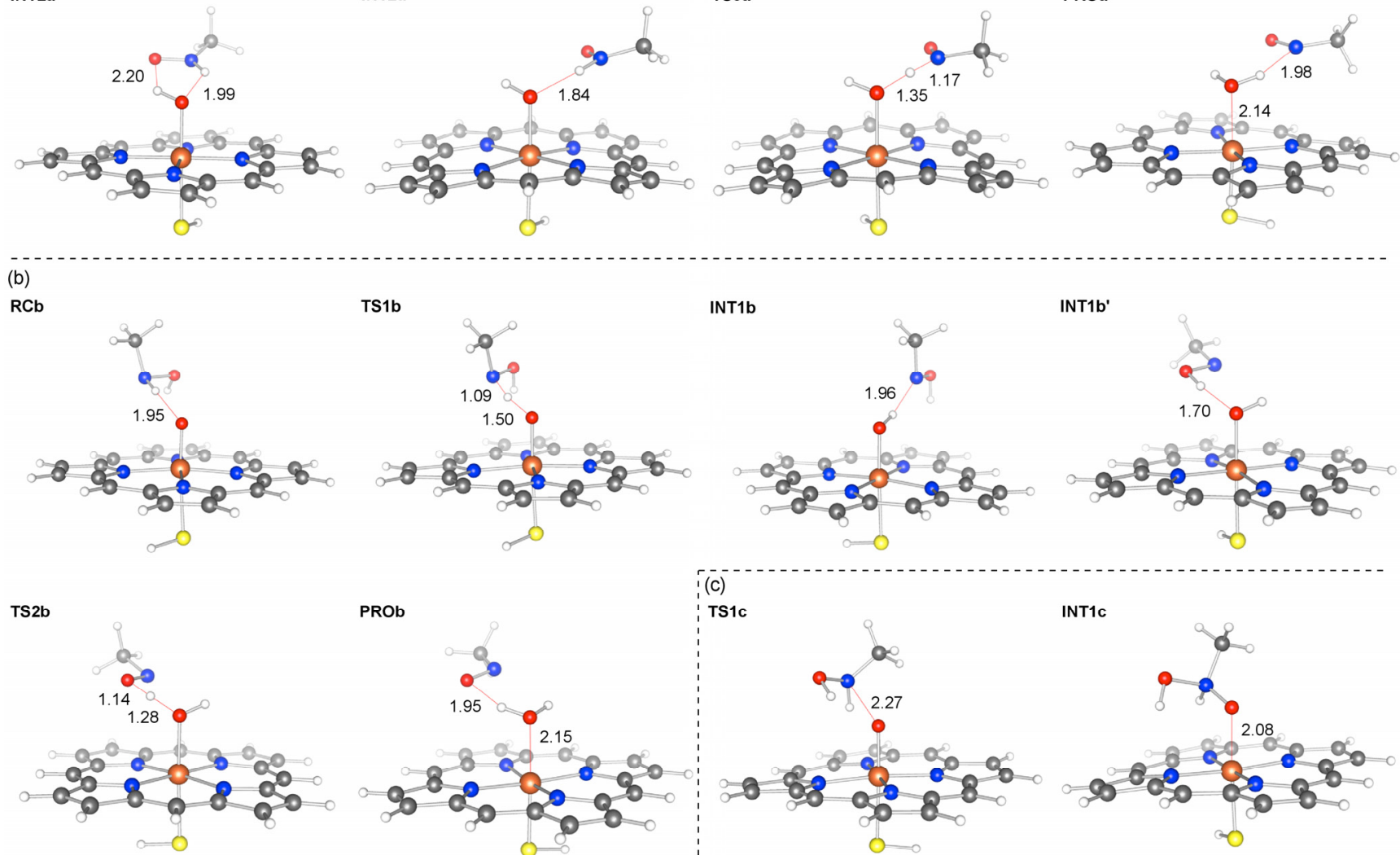

TS1b

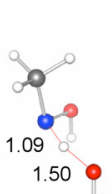

INT1b

INT1b'
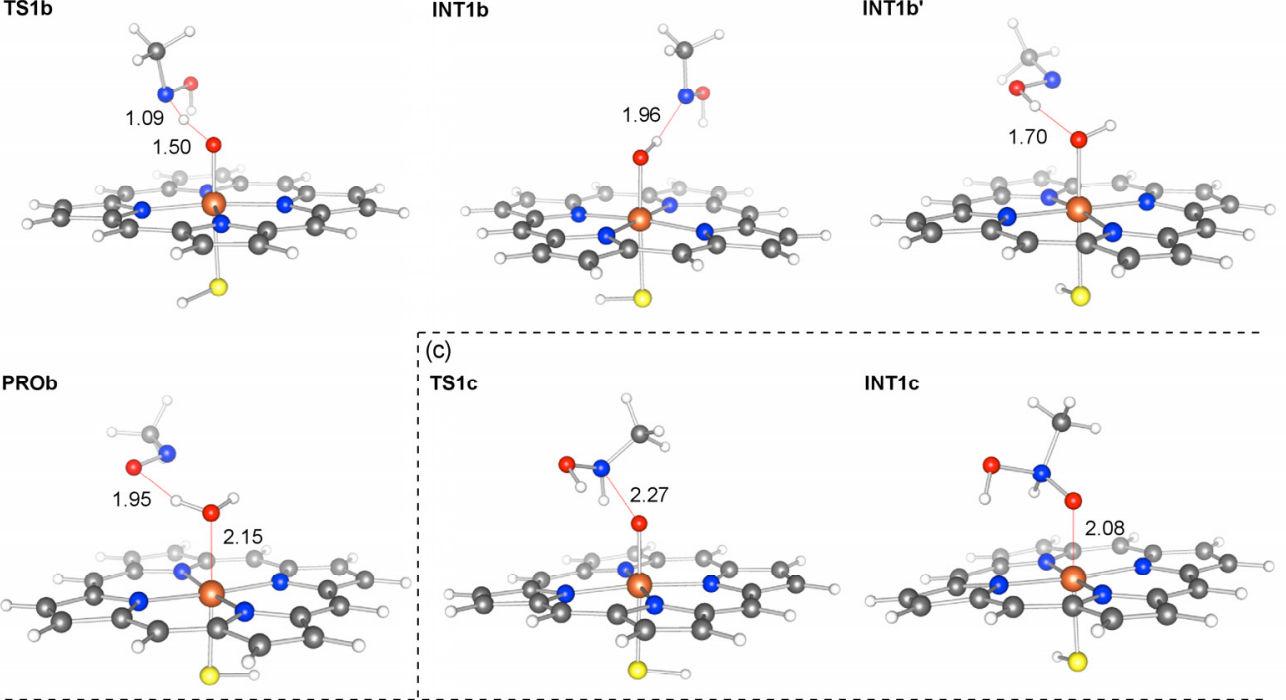

INT1c

(d)

RCd

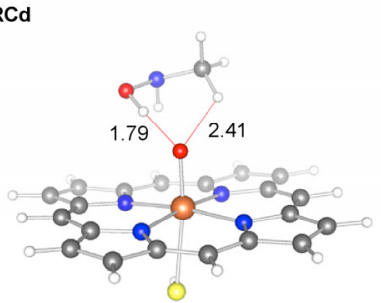

TS1d

PROd
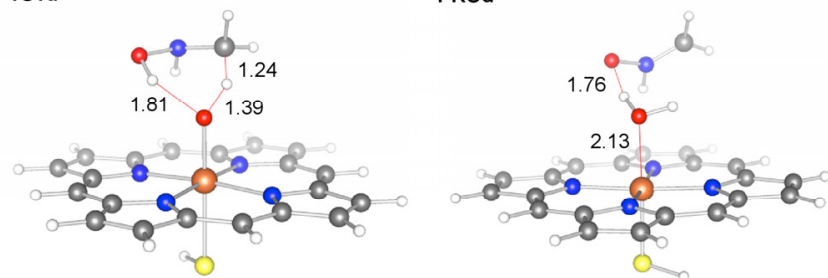

\subsection{Coordination Bond in MIC}

The produced nitrosomethane species will coordinate to the heme iron to form a MIC. We investigated the nature of the coordination bond in the MIC, considering two different types of MICs, MIC(II) and MIC(III), in which the central iron has a formal oxidation state of +2 and +3 , respectively. The spin states of these complexes were assumed to be singlet and doublet (i.e., ${ }^{1} \mathrm{MIC}(\mathrm{II})$ and ${ }^{2} \mathrm{MIC}(\mathrm{III})$, where the superscripts stand for the spin multiplicity). For each of these MICs, we 
optimized the geometries of $\mathrm{N}$-bound and O-bound forms, which respectively use the $\mathrm{N}$ and the $\mathrm{O}$ atom of the nitrosomethane for the coordination to Fe. Figure 3a,b show the optimized geometries of the N-bound and O-bound forms, respectively, along with their relative energies. A comparison of the energies of these two forms clearly shows that the N-bound form is more stable in both MIC(II) (by $>11 \mathrm{kcal} / \mathrm{mol}$ ) and MIC(III) (by $>4 \mathrm{kcal} / \mathrm{mol}$ ), which is in accordance with the conventionally assumed structure (Scheme 2) and the X-ray structures of related complexes and enzymes [43,44]. Interestingly, in Figure 3a, the Fe-N distance in the N-bound geometry is seen to be shorter for MIC(II) than for MIC(III). This trend implies that the interaction may be somewhat stronger in the ferrous MIC.

Figure 3. M06/B1-optimized geometries of ${ }^{1} \mathrm{MIC}(\mathrm{II})$ and ${ }^{2} \mathrm{MIC}(\mathrm{III})$ : (a) the N-bound form and (b) the O-bound form. Key distances are given in $\AA$. The values below the geometries are relative energies (kcal/mol) obtained at the M06(SCRF)/B2 level ( ${ }^{1} \mathrm{MIC}(\mathrm{II}){ }^{2} \mathrm{MIC}(\mathrm{III})$ ), while the values in parentheses are relative energies obtained at the B3LYP(SCRF)/B2 level.

(a)

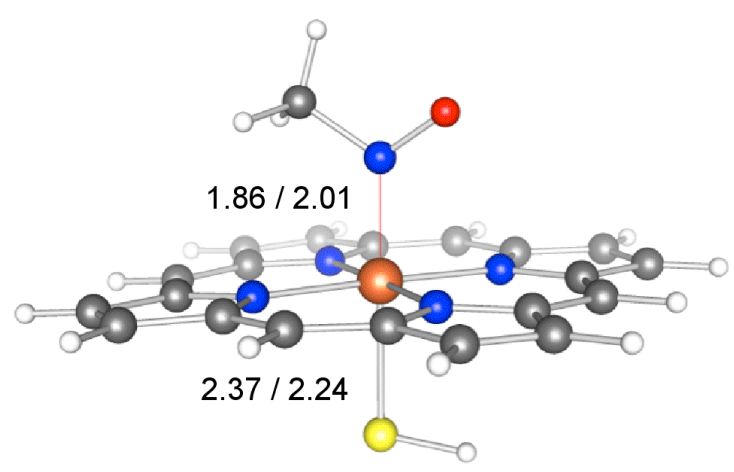

$0.0 / 0.0$

$(0.0 / 0.0)$ (b)

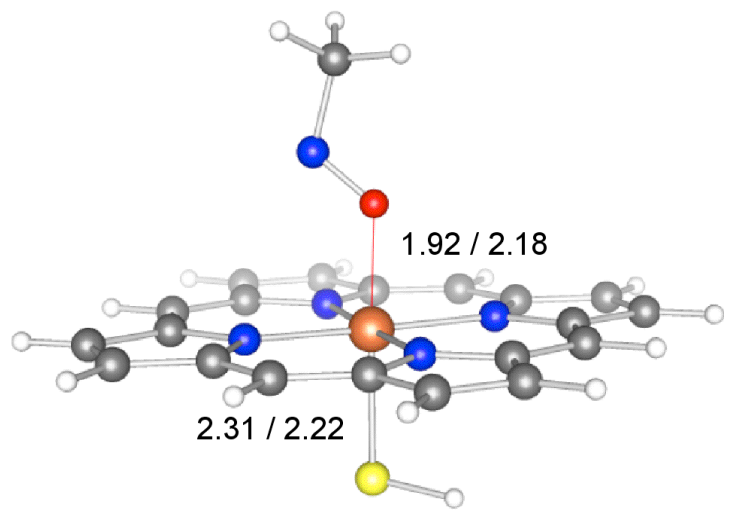

$16.1 / 7.8$

(11.8/4.2)

To evaluate the binding strengths of these MICs more quantitatively, we calculated the interaction energies $(\Delta E)$, or the energy change for the following processes:

$$
\begin{gathered}
{ }^{5}\left[\mathrm{Fe}^{\mathrm{II}}(\text { Por })(\mathrm{SH})\right]+\text { nitrosomethane } \rightarrow{ }^{1} \mathrm{MIC}(\mathrm{II}) \\
{ }^{6}\left[\mathrm{Fe}^{\mathrm{III}}(\text { Por })(\mathrm{SH})\right]+\text { nitrosomethane } \rightarrow{ }^{2} \mathrm{MIC}(\mathrm{III})
\end{gathered}
$$

where Por and $\mathrm{SH}$ denote the porphine and $\mathrm{SH}^{-}$ligands, respectively. In other words, we evaluated how the potential energy changes, when a pentacoordinate heme in a high-spin ground state binds to nitrosomethane to form a MIC [11]. Table 1 summarizes the calculated $\Delta E$ data. Three methods were examined, i.e., M06, B3LYP, and B3LYP-D3. The calculations with the M06 functional predicted that the complex formation in MIC(II) and MIC(III) is a stabilizing and a destabilizing process, respectively, whereas B3LYP and B3LYP-D3 predicted that both interactions are favorable. Despite some differences in the magnitudes of $\Delta E$, all methods predicted that the MIC formation is more favorable for the ferrous ( $\mathrm{Fe}(\mathrm{II}))$ heme, which is consistent with the experimental observation that the iron in a nitrosoalkane MIC has a ferrous state [40]. 
Table 1. Interaction energies (kcal/mol) calculated for the MIC(II) and MIC(III) ${ }^{a}$.

\begin{tabular}{cccc}
\hline & $\Delta \boldsymbol{E}($ M06 $)$ & $\Delta \boldsymbol{E}($ B3LYP $)$ & $\Delta \boldsymbol{E}\left(\right.$ B3LYP-D3) ${ }^{\boldsymbol{b}}$ \\
\hline MIC(II) & -3.7 & -2.1 & -13.6 \\
MIC(III) & 6.8 & -0.4 & -10.5 \\
\hline
\end{tabular}

${ }^{a}$ Obtained from B2(SCRF) single-point calculations on the M06/B1-optimized geometries, with the M06/B1 zero-point energy effect included. $\Delta E$ was calculated as $E(\mathrm{MIC})-E([\mathrm{Fe}(\mathrm{Por})(\mathrm{SH})])-E($ nitrosomethane);

${ }^{b}$ With B3LYP-D3(BJ) corrections.

\subsection{Energy Decomposition Analysis of MIC}

The nature of coordination bonds was further investigated using energy decomposition analysis (EDA). Table 2 summarizes the decomposed energy terms for the interaction between nitrosomethane and the ferrous or ferric heme group in the MIC (see Scheme 3 and Figure 3a). It should be noted that the total "interaction energy" evaluated here is somewhat different from those obtained from Equations (1) and (2) (Table 1) in that (i) the geometries of the fragments are the same as those in the MICs, and (ii) the $[\mathrm{Fe}(\mathrm{Por})(\mathrm{SH})]$ fragments are in low-spin states. Despite these differences, the total interaction energy was again slightly larger for MIC(II). The stabilization due to the electrostatic $(-104.1 \mathrm{kcal} / \mathrm{mol})$ and orbital-interaction $(-67.4 \mathrm{kcal} / \mathrm{mol})$ effects is larger in MIC(II) than in MIC(III). At first glance, these results were counterintuitive in view of the smaller formal positive charge of $\mathrm{Fe}$ in MIC(II) (i.e., +2) than in MIC(III) (i.e., +3). To better understand this trend, we attempted to make a fairer comparison, performing EDA for ${ }^{1} \mathrm{MIC}(\mathrm{II})$ ', which has the same geometry as ${ }^{1} \mathrm{MIC}$ (II) except that the $\mathrm{Fe}-\mathrm{N}$ (nitrosomethane) distance in ${ }^{1} \mathrm{MIC}$ (II)' was elongated to $2.01279 \AA$, so that the $\mathrm{Fe}-\mathrm{N}$ distances in ${ }^{1} \mathrm{MIC}(\mathrm{II}){ }^{\prime}$ and ${ }^{2} \mathrm{MIC}(\mathrm{III})$ were equal. This elongation did not change the total interaction energy significantly (Table 2). Consistent with the argument based on the formal charge of $\mathrm{Fe}$, the electrostatic stabilization in ${ }^{1} \mathrm{MIC}(\mathrm{II}){ }^{\prime}(-67.9 \mathrm{kcal} / \mathrm{mol})$ was smaller than that in ${ }^{2} \mathrm{MIC}(\mathrm{III})$ $(-75.8 \mathrm{kcal} / \mathrm{mol})$ by about $8 \mathrm{kcal} / \mathrm{mol}$. The orbital interaction energies were not very different in these complexes. Interestingly, the Pauli repulsion energy for ${ }^{1} \mathrm{MIC}(\mathrm{II}){ }^{\prime}$ was smaller $(90.0 \mathrm{kcal} / \mathrm{mol})$ than that for ${ }^{2} \mathrm{MIC}(\mathrm{III})(103.1 \mathrm{kcal} / \mathrm{mol})$ by about $13 \mathrm{kcal} / \mathrm{mol}$. Our EDA data therefore suggest that the major reason the MIC(II) forms a stronger coordination bond is its intrinsically smaller Pauli repulsion. The smaller Pauli repulsion allows the two interacting fragments to come closer to each other. As a result of the bond shortening in going from ${ }^{1} \mathrm{MIC}(\mathrm{II}){ }^{\prime}$ to ${ }^{1} \mathrm{MIC}(\mathrm{II})$, the Pauli repulsion increases significantly to $148.0 \mathrm{kcal} / \mathrm{mol}$; however, the attractive electrostatic and orbital-interaction terms also increase, with these stabilizing effects slightly surpassing the Pauli destabilization. It should also be noted that the electrostatic and Pauli effects are not sufficient to fully explain the formation of a MIC, because the sum of these energy terms is positive: $22.2 \mathrm{kcal} / \mathrm{mol}$ for ${ }^{1} \mathrm{MIC}(\mathrm{II}){ }^{\prime}$ and $27.4 \mathrm{kcal} / \mathrm{mol}$ for ${ }^{2} \mathrm{MIC}(\mathrm{III})$. Clearly, the other effect, orbital interaction, plays an important role in stabilizing the complex. 
Table 2. Summary of B3LYP/TZP-EDA-derived energy terms for several MICs (in $\mathrm{kcal} / \mathrm{mol}$ ).

\begin{tabular}{cccc}
\hline Energy term & ${ }^{\mathbf{1}} \mathbf{M I C}($ II) & ${ }^{\mathbf{1}} \mathbf{M I C ( I I )}{ }^{\boldsymbol{a}}$ & ${ }^{\mathbf{2}} \mathbf{M I C ( I I I )}$ \\
\hline Electrostatic & -104.1 & -67.9 & -75.8 \\
Repulsion & 148.0 & 90.0 & 103.1 \\
Orbital interaction & -67.4 & -45.1 & -45.8 \\
Total interaction & -23.6 & -22.9 & -18.4 \\
\hline
\end{tabular}

${ }^{a}$ The Fe-N distance of the geometry of ${ }^{1} \mathrm{MIC}(\mathrm{II})$ was elongated to $2.01279 \AA$ (which is the same as the distance in ${ }^{2} \mathrm{MIC}(\mathrm{III})$ ), while keeping all the other internal coordinates unchanged.

\section{Experimental Section}

We usually use the B3LYP functional for geometry optimization when studying P450 reactions [27,29,45-47]. However, in this study, we encountered difficulties in optimizing the geometries of a few transition states. Therefore, the M06 functional [48] was used instead for geometry optimization, in conjunction with the SDD effective core potential basis set for Fe and the 6-31G* basis set for the other atoms (B1) [49,50]. Single-point energy calculations were performed for all intermediates and transition states, using the B3LYP functional and the 6-311+G(d,p) basis set (B2), while taking into account the somewhat polar nature of the enzyme active site with the IEFPCM self-consistent-reaction-field (SCRF) method $(\varepsilon=5.6968)$ [51]. Because previous studies showed that the doublet spin state is mostly the ground state in the reactions of amines [25,26,35-37,52], the doublet was considered in this study.

Besides analyzing the reaction mechanisms of MI formation, we also investigated the interaction between the nitrosoalkane MI and the heme in the MIC. The M06 functional tended to overestimate the stability of high-spin states of pentacoordinate P450 intermediates (Table S7). Therefore, we mainly used the B3LYP(SCRF)/B2//M06/B1 data for the discussion on MICs. B3LYP-D3 dispersion energy correction with the Becke-Johnson (BJ) damping was also attempted [53-57]. EDA was performed at the B3LYP/TZP level using the M06/B1-optimized geometries [58-61].

Gaussian 09 was used for almost all calculations [62], but the Amsterdam Density Functional (ADF) program was used for the EDA [63,64]. Chimera was used to draw molecular structures [65]. Full Ref. 62 is given in the Supporting Information.

\section{Conclusions}

A DFT study was undertaken to elucidate the mechanism of the P450-catalyzed conversion of $\mathrm{NMH}$ into a nitrosomethane intermediate that eventually causes P450 inhibition. Based on the energy data, we conclude that the pathways involving $\mathrm{H}$-abstraction from the $\mathrm{O}-\mathrm{H}$ or the $\mathrm{N}-\mathrm{H}$ bond are more plausible than the $\mathrm{N}$-oxidation and $\mathrm{C}-\mathrm{H}$ activation pathways. $\mathrm{H}$-abstraction from the $\mathrm{O}-\mathrm{H}$ bond was found to be slightly more favorable than $H$-abstraction from the $\mathrm{N}-\mathrm{H}$ bond. However, the latter might also occur depending on the initial configuration of $N$-alkylhydroxylamine in the active site of a P450. The analysis of the coordination bond of MICs showed that the binding energy of MIC(II) is greater than that of MIC(III). Additional EDA showed that the Pauli repulsion is intrinsically smaller in 
MIC(II) than in MIC(III), which appears to be the main reason the MIC(II) forms a somewhat tighter complex.

\section{Acknowledgments}

This work was supported by a Nanyang Assistant Professorship. We thank the High Performance Computing Centre at Nanyang Technological University for computer resources.

\section{Conflicts of Interest}

The authors declare no conflict of interest.

\section{References}

1. Cytochrome P450: Structure, Mechanism and Biochemistry, 3rd ed.; Ortiz de Montellano, P.R., Ed.; Kluwer/Plenum Publishers: New York, NY, USA, 2005.

2. Omura, T. Forty years of cytochrome P450. Biochem. Biophys. Res. Commun. 1999, 266, 690-698.

3. Sligar, S.G.; Makris, T.M.; Denisov, I.G. Thirty years of microbial P450 monooxygenase research: Peroxo-heme intermediates - The central bus station in the heme oxygenase catalysis. Biochem. Biophys. Res. Commun. 2005, 338, 346-354.

4. Groves, J.T. Key elements of the chemistry of cytochrome P-450: The oxygen rebound mechanism. J. Chem. Educ. 1985, 62, 928-931.

5. Dawson, J.H.; Sono, M. Cytochrome P450 and chloroperoxidase: Thiolate ligated heme enzymes. Spectroscopic determination of their active site structures and mechanistic implications of thiolate ligation. Chem. Rev. 1987, 87, 1255-1276.

6. Guengerich, F.P. Common and uncommon cytochrome P450 reactions related to metabolism and chemical toxicity. Chem. Res. Toxicol. 2001, 14, 611-650.

7. Newcomb, M.; Toy, P.H. Hypersensitive radical probes and the mechanisms of cytochrome P450 catalyzed hydroxylation reactions. Acc. Chem. Res. 2000, 33, 449-455.

8. Sevrioukova, I.F.; Poulos, T.L. Understanding the mechanism of cytochrome P450 3A4: Recent advances and remaining problems. Dalton Trans. 2013, 42, 3116-3126.

9. Denisov, I.G.; Makris, T.M.; Sligar, S.G.; Schlichting, I. Structure and chemistry of cytochrome P450. Chem. Rev. 2005, 105, 2253-2278.

10. Meunier, B.; de Visser, S.P.; Shaik, S. Mechanism of oxidation reactions catalyzed by cytochrome P450 enzymes. Chem. Rev. 2004, 104, 3947-3980.

11. Shaik, S.; Kumar, D.; de Visser, S.P.; Altun, A.; Thiel, W. Theoretical perspective on the structure and mechanism of cytochrome P450 enzymes. Chem. Rev. 2005, 105, 2279-2328.

12. Shaik, S.; Hirao, H.; Kumar, D. Reactivity patterns of P450 enzymes: Multifunctionality of the active species, and the two states-two oxidants conundrum. Nat. Prod. Rep. 2007, 24, 533-552.

13. Shaik, S.; Hirao, H.; Kumar, D. Reactivity of high-valent iron-oxo species in enzymes and synthetic reagents: A tale of many states. Acc. Chem. Res. 2007, 40, 532-542.

14. Shaik, S.; Cohen, S.; Wang, Y.; Chen, H.; Kumar, D.; Thiel, W. P450 enzymes: Their structure, reactivity and selectivity modeled by QM/MM calculations. Chem. Rev. 2010, 110, 949-1017. 
15. Pelkonen, O.; Turpeinen, M.; Hakkola, J.; Honkakoski, P.; Hukkanen, J.; Raunio, H. Inhibition and induction of human cytochrome P450 enzymes: Current status. Arch. Toxicol. 2008, 82, 667-715.

16. Lin, J.H.; Lu, A.Y.H. Inhibition and induction of cytochrome P450 and the clinical implications. Clin. Pharmacokinet. 1998, 35, 361-390.

17. Zhou, S.F.; Chan, S.Y.; Goh, B.C.; Chan, E.; Duan, W.; Huang, M.; McLeod, H.L. Mechanism-based inhibition of cytochrome P450 3A4 by theraputic drugs. Clin. Pharmacokinet. 2005, 44, 279-304.

18. Fontana, E.; Dansette, P.M.; Poli, S.M. Cytochrome P450 enzymes mechanism based inhibitors: Common sub-structures and reativity. Curr. Drug Metab. 2005, 6, 413-454.

19. Kalgutkar, A.S.; Obach, R.S.; Maurer, T.S. Mechanism-based inactivation of cytochrome P450 enzymes: Chemical mechanism, structure activity relationships and relationships to clinical drug drug interactions and idiosyncratic adverse drug reactions. Curr. Drug Metab. 2007, 8, 407-447.

20. Zhou, S.F. Drugs behave as substrates, inhibitors and inducers of human cytochrome P450 3A4. Curr. Drug Metab. 2008, 9, 310-322.

21. Hollenberg, P.F.; Kent, U.M.; Bumpus, N.N. Mechanism based inactivation of human cytochrome P450s: Experimental characterization, reactive intermediates, and clinical implications. Chem. Res. Toxicol. 2008, 21, 189-205.

22. Orr, S.T.M.; Ripp, S.L.; Ballard, T.E.; Henderson, J.L.; Scott, D.O.; Obach, R.S.; Sun, H.; Kalgutkar, A.S. Mechanism-based inactivation (MBI) of cytochrome P450 enzymes: Structure activity relationships and discovery strategies to mitigate drug-drug interaction risks. J. Med. Chem. 2012, 55, 4896-4933.

23. Kamel, A.; Harriman, S. Inhibition of cytochrome P450 enzymes and biomedical aspects of mechanism-based inactivation (MBI). Drug. Discov. Today 2013, 10, e177-e189.

24. De Visser, S.P.; Kumar, D.; Shaik, S. How do aldehyde side products occur during alkane epoxidation by cytochrome P450? Theory reveals a state specific multistate scenario where the high-spin component leads to all side products. J. Inorg. Biochem. 2004, 98, 1183-1193.

25. Rydberg, P.; Olsen, L. Do two different reaction mechanisms contribute to the hydroxylation of primary amines by cytochrome P450? J. Chem. Theory Comput. 2011, 7, 3399-3404.

26. Taxak, N.; Desai, P.V.; Patel, B.; Mohutsky, M.; Klimkowski, V.J.; Gombar, V.; Bharatam, P.V. Metabolic-intermediate complex formation with cytochrome P450: Theoretical studies in elucidating the reaction pathway for the generation of reactive nitroso intermediate. J. Comput. Chem. 2012, $33,1740-1747$.

27. Hirao, H.; Cheong, Z.H.; Wang, X.Q. Pivotal role of water in terminating enzymatic function: A density functional theory study of the mechanism-based inactivation of cytochromes P450. J. Phys. Chem. B 2012, 116, 7787-7794.

28. Taxak, N.; Patel, B.; Bharatam, P.V. Carbene generation by cytochromes and electronic structure of heme-iron-porphyrin-carbene complex: A quantum chemical study. Inorg. Chem. 2013, 52, 5097-5109. 
29. Hirao, H.; Chuanprasit, P.; Cheong, Y.Y.; Wang, X. How is a metabolic intermediate formed in the mechanism-based inactivation of cytochrome $\mathrm{P} 450$ by using 1,1-dimethylhydrazine: Hydrogen abstraction or nitrogen oxydation. Chem. Eur. J. 2013, 19, 7361-7369.

30. Ma, B.; Prueksaritanont, T.; Lin, J.H. Drug interactions with calcium channel blockers: Possible involvement of metabolite-intermediate complexatoin with CYP3A. Drug Metab. Dispos. 2000, $28,125-130$.

31. Mansuy, D. Formation of reactive intermediates and metabolites: Effects of macrolide antibiotics on cytochrome P450. Pharmacol. Ther. 1987, 33, 41-45.

32. Dansette, P.M.; Delaforge, M.; Sartori, E.; Beaune, P.; Jaouen, M.; Mansuy, D. Drug interactions with macrolide antibiotics: Specificity of pseudo suicide inhibition and induction of cytochrome P450. Adv. Exp. Med. Biol. 1986, 197, 155-162.

33. Reidy, G.F.; Mehta, I.; Murray, M. Inhibition of oxidative drug metabolism by orphenadrine: In vitro and in vivo evidence for isozyme-specific complexation of cytochrome $\mathrm{P} 450$ and inhibition kinetics. Mol. Pharmacol. 1989, 35, 736-743.

34. Buening, M.K.; Franklin, M.R. SKF 525-A inhbition, induction and $452 \mathrm{~nm}$ complex formation. Drug Metab. Dispos. 1976, 4, 244-255.

35. Rydberg, P.; Ryde, U.; Olsen, L. Sulfoxide sulfur and nitrogen oxidation and dealkylation by cytochrome P450. J. Chem. Theory Comput. 2008, 4, 1369-1377.

36. Li, C.; Wu, W.; Cho, K.B.; Shaik, S. Oxidation of tertiary amnines by cytochrome P450-kinetic isotope effect as a spin state reactivity probe. Chem. Eur. J. 2009, 15, 8492-8503.

37. Roberts, K.M.; Jones, J.P. Anillinic $N$-oxides support cytochrome P450-mediated $N$-dealkylation through hydrogen-atom transfer. Chem. Eur. J. 2010, 16, 8096-8107.

38. Hanson, K.L.; VandenBrink, B.M.; Babu, K.N.; Allen, K.E.; Nelson, W.L.; Kunze, K.L. Sequential metabolism of secondary alkyl amine to metabolic-intermediate complexes: Opposing roles for secondary hydroxylamine primary amine metabolites of desipramine, $(S)$-fluoxetine and N-desmethyldiltiazem. Drug Metab. Dispos. 2010, 38, 963-972.

39. Correia, M.A.; Ortiz de Montellano, P.R. Inhibition of Cytochrome P450 Enzymes. In Cytochrome P450: Structure, Mechanism, and Biochemistry, 3rd ed.; Ortiz de Montellano, P.R., Ed.; Kluwer Academic/Plenum Publishers: New York, NY, USA, 2005; pp. 247-322.

40. Lindeke, B.; Paulsen, U.; Anderson, E. Cytochrome P455 complex formation in the metabolism of phenylalkylamines-IV: Spectral evidences for metabolic conversion of methamphetamine to $N$-hydroxymethamphetamine. Biochem. Pharmacol. 1979, 28, 3629-3635.

41. Franklin, M.R. The formation of $455 \mathrm{~nm}$ complex during cytochrome P-450-dependent $N$-hydroxyamphetamine metabolism. Mol. Pharmacol. 1974, 10, 975-985.

42. Lindeke, B.; Anderson, E.; Lundkvist, G.; Jonsson, U.; Eriksson, S.O. Autoxidation of $N$-hydroxyamphetamine and $N$-hydroxyphentermine. The formation of 2-nitroso-1-phenyl-propanes and 1-phenyl-2-propanone oxime. Acta Pharm. Suec. 1975, 12, 183-198.

43. Mansuy, D.; Battioni, P.; Chottard, J.C.; Riche, C.; Chiaroni, A. Nitrosoalkane complexes of iron-porphyrins: Analogy between the bonding properties of nitrosoalkanes and dioxygen. J. Am. Chem. Soc. 1983, 105, 455-463.

44. Copeland, D.M.; West, A.H.; Richter-Addo, G.B. Crystal structures of ferrous horse heart myoglobin complexed with nitric oxide and nitrosoethane. Proteins: Struct. Funct. Genet. 2003, 53, 182-192. 
45. Becke, A.D. Density functional thermochemistry III. The role of exact exchange. J. Chem. Phys. 1993, 98, 5648-5652.

46. Lee, C.; Yang, W.; Parr, R.G. Development of the Colle-Salvetti correction energy formula into a functional of the electron density. Phys. Rev. B 1988, 37, 785-789.

47. Vosko, S.H.; Wilk, L.; Nusair, M. Accurate spin-dependant electron liquid correlation energies for local spin density calculations: A critical analysis. Can. J. Phys. 1980, 58, 1200-1211.

48. Zhao, Y.; Truhlar, D.G. The M06 suite of density functionals for main group thermochemistry, thermochemical kinetics, noncovalent interactions, excited states, and transition elements: Two new functionals and systematic testing of four M06-class functionals and 12 other functionals. Theor. Chem. Acc. 2008, 120, 215-241.

49. Dolg, M.; Wedig, U.; Stoll, H.; Preuss, H. Energy-adjusted ab initio pseudopotentials for the first row transition elements. J. Chem. Phys. 1987, 86, 866-872.

50. Hehre, W.; Radom, L.; Schleyer, P.R.; Pople, J.A. Ab Initio Molecular Orbital Theory; John Wiley \& Sons: New York, NY, USA, 1986.

51. Tomasi, J.; Mennucci, B.; Cammi, R. Quantum mechanical continuum solvation models. Chem. Rev. 2005, 105, 2999-3093.

52. Ji, L.; Schüürmann, G. Model and mechanism: $N$-hydroxylation of primary aromatic amines by Cytochrome P450. Angew. Chem. Int. Ed. 2013, 52, 744-748.

53. Grimme, S.; Antony, J.; Ehrlich, S.; Krieg, H. A consistent and accurate ab initio parametrization of density functional dispersion correction (DFT-D) for the 94 elements H-Pu. J. Chem. Phys. 2010, 132, 154104-154123.

54. Grimme, S.; Ehrlich, S.; Goerigk, L. Effect of the damping function in dispersion corrected density functional theory. J. Comput. Chem. 2011, 32, 1456-1465.

55. Johnson, E.R.; Becke, A.D. A post Hartree-Fock model for intermolecular interactions. J. Chem. Phys. 2005, 123, 024101-024108.

56. Becke, A.D.; Johnson, E.R. A density functional model of the dispersion interaction. J. Chem. Phys. 2005, 123, 154101-154110.

57. Johnson, E.R.; Becke, A.D. A post Hartree-Fock model for intermolecular interactions. Inclusion of higher order corrections. J. Chem. Phys. 2006, 124, 174104-174113.

58. Kitaura, K.; Morokuma, K. A new energy decomposition scheme for molecular interactions within the Hartree-Fock approximation. Int. J. Quantum Chem. 1976, 10, 325-340.

59. Ziegler, T.; Rauk, A. A theoretical study of the ethylene-metal bond in complexes between $\mathrm{Cu}^{+}$, $\mathrm{Ag}^{+}, \mathrm{Au}^{+}, \mathrm{Pt}^{0}$, or $\mathrm{Pt}^{2+}$ and ethylene, based on the Hartree-Fock-Slater transition-state method. Inorg. Chem. 1979, 18, 1558-1565.

60. Ziegler, T.; Rauk, A. Carbon monoxide, carbon monosulfide, molecular nitrogen, phosphorus trifluoride, and methyl isocyanide as $\sigma$ donors and $\pi$ acceptors. A theoretical study by the Hartree-Fock-Slater transition-state method. Inorg. Chem. 1979, 18, 1755-1759.

61. Von Hopffgarten, M.; Frenking, G. Energy decomposition analysis. WIREs Comput. Mol. Sci. 2012, 2, 43-62.

62. Frisch, M.J.; Trucks, G.W.; Schlegel, H.B.; Scuseria, G.E.; Robb, M.A.; Cheeseman, J.R.; Scalmani, G.; Barone, V.; Mennucci, B.; Petersson, G.A.; et al. Gaussian 09, Revision B.01; Gaussian Inc.: Wallingford, CT, USA, 2010. 
63. Fonseca Guerra, C.; Snijders, J.G.; te Velde, G.; Baerends, E.J. Towards an order-N DFT method. Theor. Chem. Acc. 1998, 99, 391-403.

64. Te Velde, G.; Bickelhaupt, F.M.; Baerends, E.J.; Fonseca Guerra, C.; van Gisbergen, S.J.A.; Snijders, J.G.; Ziegler, T. Chemistry with ADF. J. Comput. Chem. 2001, 22, 931-967.

65. Pettersen, E.F.; Goddard, T.D.; Huang, C.C.; Couch, G.S.; Greenblatt, D.M.; Meng, E.C.; Ferrin, T.E. UCSF Chimera-A visualization system for exploratory research and analysis. J. Comput. Chem. 2004, 25, 1605-1612.

(C) 2013 by the authors; licensee MDPI, Basel, Switzerland. This article is an open access article distributed under the terms and conditions of the Creative Commons Attribution license (http://creativecommons.org/licenses/by/3.0/). 